\title{
Time to embrace the promise of virtual health care
}

- Cite as: CMAJ 2019 March 18;191:E320-1. doi: 10.1503/cmaj.109-5720

Posted on cmajnews.com on Feb. 27, 2019.

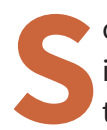
ometimes receiving primary care is onerous for patients. Carving time out of busy workdays, finding childcare, or covering the transportation costs of getting to a clinic are a few of the logistical demands. Conducting primary care visits with readily available communications technologies, when appropriate, could save not only hassle for patients but also millions of dollars for health care systems, according to Stephen Powis, the national medical director of NHS (National Health Service) England.

"The time has come to grasp this nettle," he said in a recent report for the United Kingdom's Royal College of Physicians that itemized examples of how those savings could be achieved with available secure video-link platforms.

Canadian patients also appear to be ready for such innovations, as indicated by a 2018 Canada Health Infoway survey of 2406 adults. Just under half of respondents said they would like to interact with a health care provider by video, and $74 \%$ expressed a desire to use electronic technology for routine interactions like prescription renewals. Only $4 \%$ of those surveyed had actually engaged in such virtual visits, but those that had were positive.

"That's indeed the perspective of patients who have had this experience. It saved them time - it's super convenient - and this is how they would expect the health care system of the future to treat them," says Chad Leaver, director of applied research with Canada Health Infoway, an independent, not-for-profit federally funded agency that has explored the prospects of virtual health care.

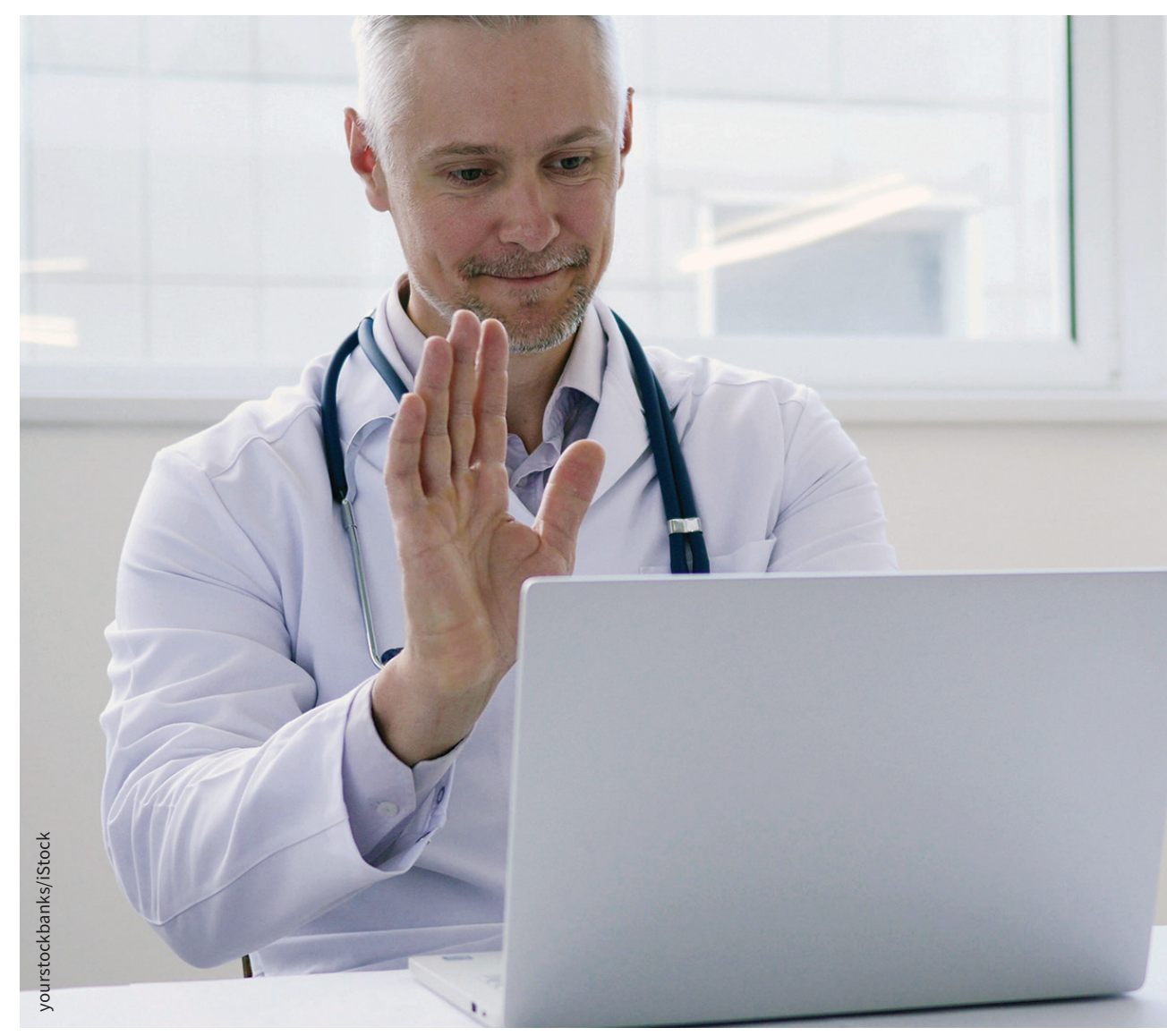

The technology to conduct virtual primary visits is secure and widely available.

Leaver has analyzed the impact of virtual visits, coauthoring a British Columbia study of some 5441 patients and 144 physicians over the course of a year. A key finding was that patients who visited their doctors virtually wound up making fewer visits in person than patients who did not take advantage of this technology.

"This is a signal that those patients were getting the care they needed, when they needed it, and didn't end up going to the doctor more over the next six months," says Leaver. It also suggests that virtual visits complement and replace direct clinical visits, rather than simply adding to the overall cost of the system and workload of physicians.

Although Canada initially championed "telemedicine" as a means of connecting urban-based caregivers with patients in more remote locations, the attendant hardware and software have become much more widely accessible and has the potential to be used more broadly. That being 
said, proponents of this approach remain aware of its limitations. Among them is Dr. David Marsh, chief medical director for Canadian Addiction Treatment Centres, who has been consulting virtually with patients since 2012 .

"When I started doing addiction medicine by telemedicine, I expected it would be harder to get to know the patients," he says. "What I've discovered, seeing the same patient month-in, month-out, is that over time I can get to know them just as well as if they were in-person."

Marsh insists on guarding the privacy of patients by having them attend the con- trolled environment of the Ontario Telemedicine Network's satellite clinics, where the link will not just be secure, but on-site staff will also be able to indicate anything that might not be obvious from a video feed. Such details could include more subtle signs of a patient's ongoing substance abuse, as well as who accompanied the individual to the clinic.

"I don't worry about their privacy being hacked or stolen," says Marsh. "But I do want to know who's around the patient."

This kind of virtual visit model is just one of many being tried in different jurisdictions across the country, right down to the level of individual clinics in municipalities. The real challenge, Leaver concludes, will be assessing the value of each model and helping doctors make virtual visits a regular part of providing health care, which could affect fundamental matters such as physician remuneration or clinical practice guidelines.

"They need support to appropriately integrate virtual care services into the model of care, whether it be for specialists or primary care doctors," he concludes. "That's more work that needs to be done."

Tim Lougheed, Bath, Ontario 